\title{
TOWARDS CLASSIFYING SOCIOCULTURAL ASPECTS IN GLOBAL SOFTWARE DEVELOPMENT
}

Yoji Massago ${ }^{1}$ (D) http://orcid.org/0000-0002-7998-4027

Gislaine Camila Lapasini Leal ${ }^{2}$ (D) http://orcid.org/0000-0001-8599-0776

Renato Balancieri' (D) http://orcid.org/0000-0002-8532-2011

Edwin Vladimir Cardoza Galdamez ${ }^{2}$ (1) http://orcid.org/0000-0002-1763-9332

'Department of Computer Science, State University of Maringá, Maringá, PR, Brazil

${ }^{2}$ Department of Production Engineering, State University of Maringá, Maringá, PR, Brazil

\begin{abstract}
The geographical, temporal distances and socio-cultural differences are the biggest challenges for Global Software Development (GSD). In GSD, it is necessary to deal with behaviors, values and skills of the team members, conflicts, rework, delays, etc. can influence a software production process. The objective of this paper is to identify the sociocultural aspects and propose a classification structure under different analytical perspectives in order to offer adequate support to the management of GSD teams. A systematic mapping and proposal an approach that classifies aspects in three perspectives: collaboration, people and external. The analysis allows the project manager to make decisions about the performance of human resources and mitigate problems arising from communication, cooperation and coordination, generating better results in indicators of productivity, quality and efficiency of GSD teams.
\end{abstract}

Keywords: Distributed Software Development, Global Software Development, Sociocultural Aspects, Classification, Systematic Mapping.

Manuscript first received: 2016/06/30. Manuscript accepted: 2018/05/26

Address for correspondence:

Yoji Massago, Department of Computer Science, State University of Maringá, Paraná, Brazil.

E-mail: yojimassago@gmail.com

Gislaine Camila Lapasini Leal, Department of Production Engineering, State University of Maringá, Paraná, Brazil. Email: cammyleal@gmail.com

Renato Balancieri, Department of Computer Science, State University of Maringá, Paraná, Brasil.

E-mail: renatobalancieri@gmail.com

Edwin Vladimir Cardoza Galdamez, Department of Production Engineering, State University of Maringá, Paraná, Brazil.

E-mail: evcgaldamez@uem.br 


\section{INTRODUCTION}

The growing demand for software products has caused organizational changes in the industry, mainly those related to manage aspects that improve software quality, reduce production costs and product delivery time to the customer / user. It is observed that these aspects depend on the practices adopted to promote interaction, exchange of knowledge, alignment of activities and complement the expertise of the people involved. In the production process, it is necessary to implement agile and lean development strategies that improve the performance of human resources, since it is one of the limited resources of software development. One of the main industry initiatives is to opt for the distribution of the development process, featuring the Distributed Software Development (DSD) (Damian 2002; Agerfalk et al. 2005).

The DSD is characterized by the creation of groups in which people working together, but in different places (Carmel, 1999; Herbsleb and Moitra, 2001). This dispersion may occur at various levels such as within a region (cities), country, or even in different countries. People in multiple countries are a DSD instance, called Global Software Development (GSD) (Karolak, 1999).

According to Carmel (1999), Geographical Distance, Temporal Distance and Cultural Differences, are the factors that differentiate the GSD of traditional software development. The Geographical Distance is related to the physical distance and the Temporal Distance is characterized by the difference in time zones.

Cultural differences are defined by socio-cultural aspects presented among team members (Carmel, 1999), such as Language, Religion, Moral/Ethics etc. In GSD context, the lack of social and cultural management characteristics of the teams can create communication problems, collaboration, performance management, among others, which often cause failure (delays, errors) of a project (Prikladnicki et al., 2006) (Casey, 2011).

Olson and Olson (2004) quote that the culture defines the way that people think, their motivations and how to categorize things. Babar et al. (2014), Bellur (2006), Agerfalk et al. (2005) and Prikladnicki et al. (2005) also describe different results on the social aspects and/or cultural impact directly on the GSD performance, highlighting the influence of different languages, distances, sex, and trust, among others.

So, it is observed that to improve the results of a software project developed adopting GSD strategy is necessary to plan, analyze and evaluate the social and cultural aspects present or that characterize the culture and social relationships between the teams (Casey, 2011). Therefore, the purpose of this paper is to propose a systematization of social and cultural aspects from three perspectives (collaborative, people and external) from performance management to direct and improve the efficiency, effectiveness and productivity of GSD teams, thereby reducing the delivery time and rework the software project.

This way it was defined the following research questions: RQ1: What sociocultural aspects impact the performance of GSD teams? R Q2: How can sociocultural aspects be classified?

The proposal links and features sociocultural aspects - identified in the literature through a systematic mapping defined as critical to the performance of the GSD teams such as: Language, Power Distance, Individualism versus Collectivism, Long Term versus Short Term Orientation, Uncertainty Avoidance , Masculinity versus Femininity, Communication Style, Legislation/bureaucracy, Religion, Different Work Practices, Moral/Ethics etc. Sociocultural aspects fundamental to improving 
collaboration between teams, motivate and integrate people and answer external requirements to industry.

In the next section, the methodological procedures used in the research are presented. Then are highlighted the cultural aspects identified by the systematic review. Later details the perspectives proposals to address and analyze the socio-cultural aspects. In the last section, the contributions are discussed and future researches are highlighted.

\section{METHODOLOGY}

First, the research is characterized regarding to its nature, the approach to the problem, the aimed objectives, and procedures adopted. In relation to nature, the research is classified as basic because it is aimed at acquiring new knowledge, specifically the problem related to socio-cultural aspects involved in global software development. Regarding to approach of the problem, the research is qualitative; there is the interpretation of phenomena and attribution of meanings, not predicting the quantification of data. With respect the goals of this research is classified as descriptive and exploratory. It is exploratory because it seeks greater familiarity with the problem, in order to make it explicit and enable the formulation of hypotheses. It is descriptive because it aims to characterize the problem, in order to identify the probable relationships between variables. About the procedures, the research is based initially on bibliographic research and systematic mapping.

The research is structured in two steps: the systematic mapping and the proposed classification of socio-cultural aspects. The procedure of this systematic mapping was based on Da Silva et al. (2010) e Kitchenham (2004). The systematic mapping enables synthesize available research; identify gaps in current research and direct new research activities (KITCHENHAM; CHARTERS, 2007). In this paper, it is proposed to identify the sociocultural aspects considered critical to the software production process and performance of GSD teams. The activities conducted in this step are described in the next section.

The classification proposal aimed to systematize the sociocultural aspects listed from systematic mapping. This systematization represents a way of viewing aspects and, it allows separating different concepts, although they are interrelated and complementary. Therefore, it allows clarifying the concepts for analysis and systematic approach.

\section{Review Steps}

To accomplish the literature review the following steps were performed:

Review Planning: proposed to identification of the need for a revision; research question(s) specification(s); and protocol development.

Carry out the Revision: defined to identification of primary studies; selection of primary studies; and extraction and data synthesis.

\section{Research question(s) specification(s)}

The search string definition occurred in three steps:

Selection of sets of keywords related to the research question Q1: DSD/GSD, Sociocultural aspects and research/challenges. 
Selection of synonyms: selection of a collection of words with similar meanings, resulting in the following words:

a) DSD/GSD: “Distributed Development”; “Distributed Software Development”; "Distributed Teams"; "Geographically Distributed Software Development”; "Global Software Development”; "Global Software Engineering”; "Global Software Teams"; "Globally Distributed Development”; "Globally Distributed Work"; "Offshore Outsourcing”, "Offshore Software Development”; Offshore; Offshoring; "Multi-Site Software Development";

b) Sociocultural aspects: Social; Culture; Cultural; Sociocultural; Socio-Cultural;

c) Research/challenge: Challenges; Challenge; Approaches; Approach; Risk.

Search String Generation: the final Search String consisted of three sets, connected with the connective AND, and the elements of each set are connected by an OR.

\section{RESEARCHED SOURCES}

The search for studies was performed in the following search engines: (1) IEEExplore Digital Library; (2) ACM Digital Library; (3) ScienceDirect. In addition, searches were conducted at conferences bases related to the topic, focusing on GSD, such as: (1) ICGSE - International Conference on Global Software Engineering; (2) WDDS - Distributed Software Development Workshop.

\section{Studies Selection Criteria}

The following inclusion and exclusion criteria were used to select the papers:

Inclusion criteria: a) contains an answer or part of the answer to the research question Q1; b) It is accessible through the university.

Exclusion criteria: a) duplicated documents; b) research work in progress or that would be carried out with incomplete results.

\section{Studies Selection Process}

The selection of papers that compose the final collection consisted of two steps:

Assessment of papers, found by search engines, by reading their titles, in order to eliminate those that are clearly not relevant to the subject of research.

The abstracts and conclusion of the papers that have gone through step 1, were read in order to get the final set in order to get the final set.

\section{Data extraction and synthesis}

After the selection, proceeded the extraction of data from papers. The extracted data were used to build a list of sociocultural aspects cited in the papers. It is possible to observe from most to less cited social aspect and evidence of the importance that each one of them has for the GSD researches. 


\section{RESULTS}

The search period considered was from 2001 to mid-2014. The initial survey conducted in search engines and events resulted in 1794 documents. After studies selection process resulted in 43 publications, listed in Appendix.

Figure 1 shows the number of papers published per year. It is observed that in the period 2001 to 2006 the number of primary research that addressed the social and cultural aspects of GSD is reduced. However, one year after the organization of the I International Conference on Global Software Engineering, in 2006, held in Florianópolis - Brazil has identified a growing number of publications in 2007 and subsequently in 2010 and 2011. When designing a moving average for five years also identifies that, there is a steady growth during the study period.

In 2014, even in the middle of the year, 5 relevant papers to the subject of research were identified, indicating an increased interest in this research area.

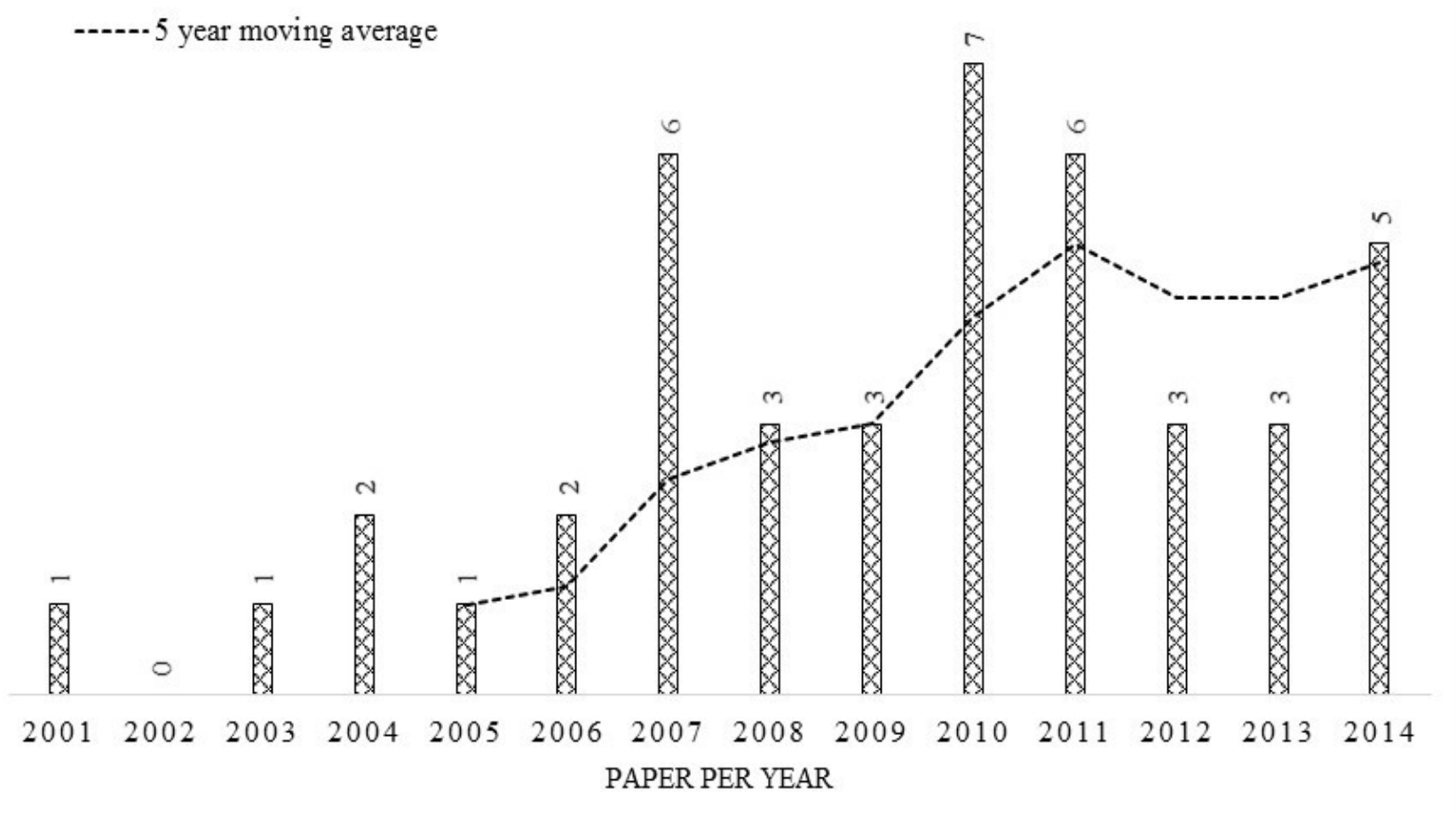

Figure 1. Publication year of selected papers.

The primary studies were published in different journal and conference or workshop. The Table 1 show that the relevant papers $(35 \%)$ found were all published in IEEE which coincides with a conference in theme: International Conference on Global Software Engineering (ICGSE), consolidating the event as one of the main dissemination channels in GSD area. 
Table 1. Result of search.

\begin{tabular}{lccccc}
\hline & IEEEXplore & ACM & ScienceDirect & Manual Search & Total \\
\hline Total Result & 294 & 1181 & 289 & 24 & 1788 \\
\hline Selected & 15 & 6 & 10 & 12 & 43 \\
\hline$\%$ & $35 \%$ & $14 \%$ & $23 \%$ & $28 \%$ & $100 \%$ \\
\hline
\end{tabular}

\section{Sociocultural aspects}

One of the largest challenges met when Global Software Development is adopted are the problems arising from cultural differences (MacGregor et al., 2005; Da Silva et al. 2010; Casey, 2011). Sociocultural aspects dealing with issues related to social and cultural differences between distributed team (Bellur, 2006). Da Silva et al., (2010) emphasize that the effect of socio-cultural aspects should not be underestimated because they amplify the difficulties involved in DSD. In this direction, to get the benefits of distributed development is necessary to know the socio-cultural aspects and understand how they can influence software development activities.

The systematic search identified 45 socio-cultural aspects, as listed on Table 2 . Table 2 highlights the identified aspects, the frequency and the works that address the socio-cultural aspect.

Table 2. Sociocultural aspects in GSD context.

\begin{tabular}{lcl}
\hline Sociocultural aspects & Frequency & \multicolumn{1}{c}{ Papers } \\
\hline Language & 22 & $\begin{array}{l}\text { S1, S5, S6, S7, S9, S12, S13, S15, S18, S20, S21, S22, S23, S24, } \\
\text { S25, S26, S30, S31, S32, S36, S39, S42 }\end{array}$ \\
\hline Power distance & 18 & $\begin{array}{l}\text { S1, S3, S7, S19, S23, S24, S28, S29, S30, S31, S33, S34, S35, S37, } \\
\text { S40, S42, S43 }\end{array}$ \\
\hline Individualism x Collectivism & 16 & $\begin{array}{l}\text { S1, S3, S16, S19, S213 S26, S27, S28, S29, S30, S31, S34, S35, } \\
\text { S37, S42, S43 }\end{array}$ \\
\hline $\begin{array}{l}\text { Long Term versus Short } \\
\text { Orientation }\end{array}$ & 15 & $\begin{array}{l}\text { S1, S3, S19, S23, S27, S28, S29, S30, S31, S34, S35, S37, S39, } \\
\text { S40, S43 }\end{array}$ \\
\hline Uncertainty Avoidance & 15 & $\begin{array}{l}\text { S1, S3, S16, S19, S23, S27, S28, S29, S30, S31, S34, S35, S37, } \\
\text { S40, S43 }\end{array}$ \\
\hline Masculinity versus Femininity & 13 & S1, S3, S19, S23, S26, S27, S28, S29, S30, S34, S35, S37, S43 \\
\hline Communication Style & 8 & S7, S13, S15, S21, S26, S39, S40, S41 \\
\hline Legislation/bureaucracy & 8 & S10, S13, S20, S25, S26, S30, S39, S42 \\
\hline Religion & 8 & S7, S11, S19, S25, S26, 29, S31, S39 \\
\hline Different Work Practices & 7 & S5, S9, S13, S15, S21, S24, S39 \\
\hline Moral/Ethics & 7 & S9, S12, S19, S20, S26, S40, S42 \\
\hline Trust & 6 & S2, S22, S26, S32, S40, S42 \\
\hline Beliefs & 5 & S7, S13, S19, S31, S39 \\
\hline Calendar differences & 5 & S13, S17, S30, S31, S39 \\
\hline Different Interpretations & 5 & S13, S15, S20, S31, S39 \\
\hline Personal Values & 5 & S12, S14, S19, S24, S32 \\
\hline Contextualization & 4 & S3, S7, S33, S41 \\
\hline Time Perception & 4 & S3, S19, S27, S28 \\
\hline Creativity & 3 & S7, S21, S40 \\
\hline Leadership & 3 & S23, S27, S40 \\
\hline & & \\
\hline
\end{tabular}


Table 2. Cont.

\begin{tabular}{lll}
\hline Sociocultural aspects & Frequency & Papers \\
\hline Motivation & 3 & $\mathrm{~S} 20, \mathrm{~S} 26, \mathrm{~S} 31$ \\
\hline Schedule Compliance & 3 & $\mathrm{~S} 20, \mathrm{~S} 26, \mathrm{~S} 42$ \\
\hline Controllability & 2 & $\mathrm{~S} 27, \mathrm{~S} 40$ \\
\hline Economic Environment & 2 & $\mathrm{~S} 26, \mathrm{~S} 39$ \\
\hline Education & 2 & $\mathrm{~S} 4, \mathrm{~S} 13, \mathrm{~S} 39$ \\
\hline Indulgence versus Restraint & 2 & $\mathrm{~S} 19, \mathrm{~S} 43$ \\
\hline Intellectual Capital & 2 & $\mathrm{~S} 11, \mathrm{~S} 38$ \\
\hline Knowledge sharing & 2 & $\mathrm{~S} 32, \mathrm{~S} 41$ \\
\hline Normative X Pragmatic & 2 & $\mathrm{~S} 19, \mathrm{~S} 28$ \\
\hline Promise fulfillment & 2 & $\mathrm{~S} 20, \mathrm{~S} 26$ \\
\hline Relationship & 2 & $\mathrm{~S} 7, \mathrm{~S} 40$ \\
\hline Response time & 2 & $\mathrm{~S} 20, \mathrm{~S} 21$ \\
\hline Work planning & 2 & $\mathrm{~S} 13, \mathrm{~S} 42$ \\
\hline Affective Culture X Neutral & 1 & $\mathrm{~S} 27$ \\
\hline Ascription X Achievement & 1 & $\mathrm{~S} 27$ \\
\hline Availability & 1 & $\mathrm{~S} 26$ \\
\hline Color & 1 & $\mathrm{~S} 1$ \\
\hline Decision Making & 1 & $\mathrm{~S} 13$ \\
\hline Determination & 1 & $\mathrm{~S} 8$ \\
\hline Effort & 1 & $\mathrm{~S} 16$ \\
\hline Hardware Import Restriction & 1 & $\mathrm{~S} 13$ \\
\hline Proactivity X Reactivity & 1 & $\mathrm{~S} 40$ \\
\hline Remuneration difference & 1 & $\mathrm{~S} 23$ \\
\hline Satisfaction & 1 & $\mathrm{~S} 9$ \\
\hline Social Capital & 1 & $\mathrm{~S} 38$ \\
\hline
\end{tabular}

Figure 2 shows the accumulated frequency of the number of publications by socio-cultural aspect and it was observed that 14 aspects have been identified in more than $70.5 \%$ of publications showing the importance in the research area and software industry. They are characterized in Table 3: language, power distance, individualism versus collectivism, Long Term versus Short Term, Orientation, Uncertainty Avoidance, Masculinity versus Femininity, Communication Style, Legislation/bureaucracy, Religion, Different Work Practices, Moral/Ethics, Trust and Beliefs. 


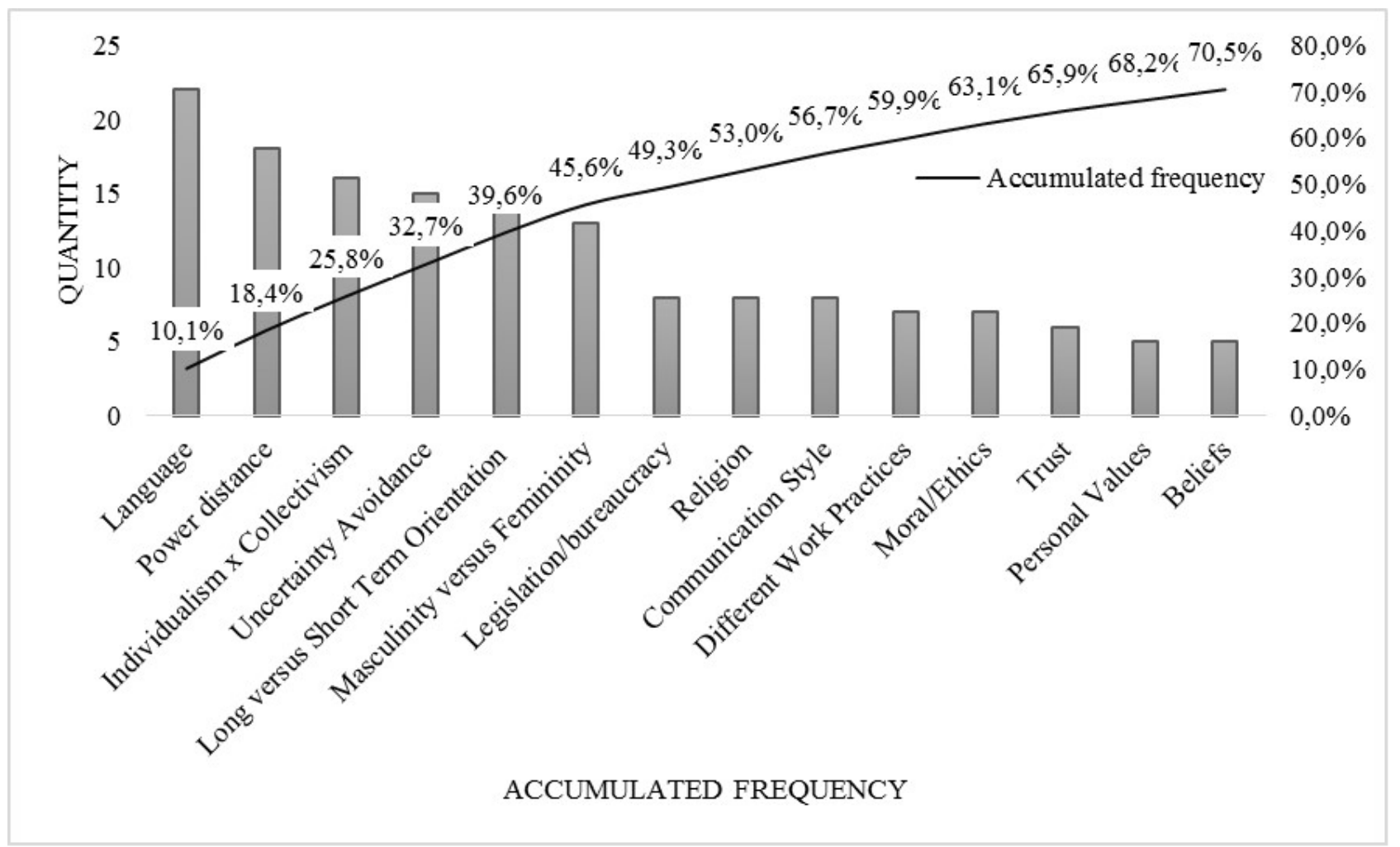

Figure 2. Accumulated frequency of sociocultural aspects

Table 3 shows the characterization of the socio-cultural aspects identified as relevant to the GSD context.

Table 3. Description of Sociocultural aspects.

\section{Sociocultural} aspects

Language

Characteristic

Considered as one of the main cultural distinctions in GSD teams. The lack of a standard language for communication between members makes difficult to develop an effective design.

Power distance

It measures the degree of inequality acceptance. In cultures with high degree of power distance, the people tend to treat inequalities as a natural thing, accepting it easily; already in cultures with low degree of Power Distance, individuals wait that they are dealt in a uniform way regardless of positions (Hofstede et al. 2010).

Individualism x Individualism has the individual himself as the main orientation, while collectivism has an Collectivism orientation directed towards common goals and objectives (MacGregor et al., 2005; Hofstede et al. 2010).

Uncertainty It Refers to the degree to which the members of a culture feel threatened / unsecured by uncertain Avoidance or unknown situations. Therefore, when a certain unexpected event occurs, the individual may feel unsure (MacGregor et al., 2005; Hofstede et al. 2010). 
Table 3. Cont.

Communication Style There are individuals who use direct communication style, while others tend to transmit the information by subtle way. There are also people who consider the message context, while others only interpret the message content itself (Lee et al. 2008).

Legislation/

bureaucracy

It points out that different sites may have their own rules or laws. So, problems related to legal aspects, such as the existence of countries with hardware import restrictions, different taxes, among others may arise (Cibotto et al. 2009).

Different Work

Practices

There are different work practices (work tools, behaviors, etc.), depending on the region, which may interfere with the performance of distributed teams (Avram, 2011).

Moral/Ethics

It Refers to the set of rules applied in daily life and continuously used by every citizen. These rules guide each individual, guiding their actions and their judgments about what is moral or immoral, right or wrong, good or bad.

It points out the extracted set of knowledge of the investigation of human behavior when trying
to explain the moral rules in a rational, reasoned, scientific and theoretical manner. It is part of
the individual's personality. This defines the actions that are "right / wrong" for the same, such
as the fulfillment of the word and time.

Trust

It is one of the most important requirements in distributed teams (Age Falk et al., 2005; Moe and Smite, 2008), because the lack of trust among team members can influence communication, collaboration. However, it is not easy to establish a sense of trust. In some countries, the word is much more than a signed document. In others, the absence of such signature may represent a lack of commitment.
Beliefs/Religion There are several religions in the contemporary world, each one with their beliefs, concepts and rules to follow. Therefore, there are different holidays, importance and significance in the colors, gestures and symbols, assignments related to gender ("role" of man and woman), among others, which can interfere with the GSD project.
Time Perception There are individuals who can focus and execute only one task at a time, proceeding sequentially (monochrome time), while others operate in parallel, performing several activities simultaneously (polychrome time) (Hofstede et al. 2010). This can influence the work planning and tasks allocation among team members.

Creativity The ability to create, produce new things, the "think outside the box" is also one of the aspects that can interfere with DSD. One example cited by Babar and Zaheadi (2013), is the need, in the requirements engineering, verification for completeness of requirements. Sometimes, may need to "think outside the box" to try to identify all the necessary requirements.

Leadership

It refers to the role, position and leader attribute. A leader is an individual who has the authority to command; person whose actions and words have an influence on the behavior and thinking of others. There are individuals with a culture related with leadership, those born leaders, or who have learned to be leaders (Jablokow, 2010). An appropriate allocation of these people can influence for the success of a project. It may have relationship to distance power. 
Table 3. Cont.

\begin{tabular}{ll}
\hline Motivation & It is the act of giving reason arouse interest for some activity. Being motivated means that, in \\
addition to have a knowledge and technical skills, the person must have interest in performing \\
a particular function (Schwalbe, 2000) cited Prickadinick (2003). The motivation directly \\
influences the performance of the realization of an activity by the individual.
\end{tabular}

Controllability It refers to the degree of avidity to dominate the surrounding environment. Thus, when a problem arises, users with a high level of controllability tend to change the environment, rather than themselves, whereas people with low culture control capability tend to change themselves rather than the situation engaging (Lee et al. 2008). This involves how an individual will react to certain cases, besides the determination to learn new things.

Economic

Environment
It points out that depending on the economic environment, there may be a different culture related to the investment time (Long Orientation or Short Term), and there may be different risks, which interfere with the aversion to uncertainty arising, for example, from an unstable economy .
Indulgence versus

Restraint
There are people living in a society, which allows using the gratification of a relatively free way, relating it to enjoy life and have fun. In other societies, the slogan "The work ennobles and dignifies man" is valued (Hofstede et al. 2010). Therefore, issues such as reward systems used in an attempt to motivation no effect on certain people.

Intellectual Capital

It refers to the set of knowledge that a person or institution has. The knowledge that individuals can acquire in different locations can be differentiated, resulting in an individual in a certain place can have distinct knowledge of others. Thus, good management of intellectual capital impact on performance in a GSD project, given the variety of people, values and locations involved.

Knowledge sharing

There are people with facility for knowledge transfer as own culture. While others retain the knowledge to himself, influencing the performance of the team and training of new members to the team (Huang and Trauth 2007).

Normative X Pragmatic
There are cultures that follow the rules, the consolidated traditions by time, while others encourage modern education as a way to prepare for the future (Hofstede, 2010). The differences in the level and style of education received by the individual impact on the knowledge acquired by him/her. Thus, the heterogeneity of education level can have an impact on the team performance. On the other hand, the different "shapes" can contribute to complementary skills or ways to solve problems.
Depending on the culture, the work planning can occur in different ways, depending on other factors such as the investment of time, workload available, among others (Cibotto et al. 2009).
Affective Culture X Neutral
Users of affective culture communicate their emotions through language and expressions directly while users of the neutral culture tend to be careful about expressing emotion (Lee et al. 2008), influencing the relationship between individuals, resulting in issues concerned to trust, social capital, among other topics related to GSD. 
Table 3. Cont.

\begin{tabular}{|c|c|}
\hline Availability & $\begin{array}{l}\text { It refers to the culture of the people regarding the working day adopted by them. Flexible } \\
\text { availability refers to availability outside normal working hours, i.e., a person easily accepts } \\
\text { work outside their regular business hours (Leal et al. 2012). This interferes, for example with } \\
\text { the communication (find meeting times compatible), allocation of people. }\end{array}$ \\
\hline Determination & $\begin{array}{l}\text { It refers to the strong inclination to be persistent in what one wants to achieve. The differences } \\
\text { in the intensity of determination and time that an individual can keep it interfere in the planning } \\
\text { / development of a project. }\end{array}$ \\
\hline Effort & $\begin{array}{l}\text { It relates to the enhancement of physical, intellectual and moral forces to carry out a project or } \\
\text { task; what it does with difficulty and commitment; animation; stimulation (Houaiss, 2001). The } \\
\text { effort may depend on external factors, such as determination, motivation and rewards. }\end{array}$ \\
\hline $\begin{array}{l}\text { Proactivity X } \\
\text { Reactivity }\end{array}$ & $\begin{array}{l}\text { There are people with culture of reacting to events (reactive) and those with ability to anticipate } \\
\text { in action, when necessary (proactive) (Vale et al., 2010). }\end{array}$ \\
\hline $\begin{array}{l}\text { Remuneration } \\
\text { difference }\end{array}$ & $\begin{array}{l}\text { Depending on the location and personal values, there may be differences in remuneration } \\
\text { between local and gender, as well as their acceptance by other members. For instance, there } \\
\text { may be people who do not accept that women have same remuneration of a man. Depending on } \\
\text { the degree of Power Distance, the salary can vary as well as its acceptance among individuals } \\
\text { (Hofstede, 2010). }\end{array}$ \\
\hline Social Capital & $\begin{array}{l}\text { Stark et al. (2007) define Social Capital as "compound of the extension of trust and } \\
\text { communication relationships that an individual has with members of his/her team, within a } \\
\text { globally distributed team". According to Boden et al. (2009), members of a team with a high } \\
\text { level of Capital Social will have more motivation to exchange knowledge with other team } \\
\text { members. }\end{array}$ \\
\hline Tradition & $\begin{array}{l}\text { Refers to the cultural heritage, legacy of beliefs, techniques, set of moral and spiritual values, } \\
\text { transmitted from generation to generation; all that is practiced by habit or custom acquired } \\
\text { (Houaiss et al. 2001). They define the part of the personal values, influencing their preferences } \\
\text { and decisions. }\end{array}$ \\
\hline
\end{tabular}

\section{Towards classifying sociocultural aspects}

Leal et al. (2012) present a classification of sociotechnical aspects into categories, stratified into groups. However, we realized the need for detail of this classification, specifically focusing on social aspects, in order to get a better understanding of the impacts that these aspects can cause in distributed teams.

Thus, based on the systematic mapping conducted and experience of the researchers involved, it is proposed a classification for the socio-cultural aspects, grouped in three levels:

Perspective: macro views of analysis under which the cultural aspects may be observed / analyzed by a set of drivers.

Driver: criteria that direct the analysis vision or approach to be taken in the perspectives.

Aspects: elements that characterize the sociocultural attributes addressed in the literature and may be associated with drivers. 
This classification was proposed in order to facilitate the understanding of the socio-cultural aspects that can influence the development management with distributed teams and with that offers support for decision making by project managers.

Table 4 illustrates the grouping performed according to the suggested levels. For the first level of classification, the following perspectives have been defined: Collaboration, Personal and External. On the second level are the Drivers: Communication, Coordination, Cooperation, and Individual aspects, Value, Law, Economics and Education.

Table 4. Classification of Sociocultural Aspects.

\begin{tabular}{|c|c|c|}
\hline Perspective & Driver & Aspect \\
\hline \multirow{13}{*}{ Collaboration } & \multirow{4}{*}{ Communication } & Language \\
\hline & & Communication Style \\
\hline & & Social Capital \\
\hline & & Knowledge Sharing \\
\hline & \multirow{4}{*}{ Coordination } & Power Distance \\
\hline & & Uncertainty Avoidance \\
\hline & & Availability \\
\hline & & Different Work Practices \\
\hline & \multirow{5}{*}{ Cooperation } & Individualism X Collectivism \\
\hline & & Trust \\
\hline & & Work Planning \\
\hline & & Knowledge Sharing \\
\hline & & Social Capital \\
\hline \multirow{13}{*}{ People } & \multirow{9}{*}{ Individual Aspects } & Determination \\
\hline & & Indulgence \\
\hline & & Proactivity X Reactivity \\
\hline & & Controllability \\
\hline & & Effort \\
\hline & & Affective Culture X Neutral \\
\hline & & Leadership \\
\hline & & Motivation \\
\hline & & Creativity \\
\hline & \multirow{4}{*}{ Value } & Beliefs or Religion \\
\hline & & Tradition \\
\hline & & Moral \\
\hline & & Ethic \\
\hline \multirow{6}{*}{ External } & \multirow{4}{*}{ Legislation } & Remuneration difference \\
\hline & & Bureaucracy \\
\hline & & Intellectual Capital \\
\hline & & Intellectual Property \\
\hline & Economy & Economic environment \\
\hline & Education & Pragmatic Culture X Normative \\
\hline
\end{tabular}


Collaboration perspective refers to the elements involved in the relationship among individuals. According to Ellis et al. (1991), collaboration is an important point to be addressed when teamwork is considered. Thus, the collaboration involves communication, coordination and cooperation (Prikladnicki and Carmel, 2014). Based on studies from the literature, communication, coordination and cooperation were defined as Drivers. According to Fuks et al. (2004) and Oliveira et al. (2007) the communication is related to the exchange of information between people, involving the interaction between individuals, a dialogue event, a context and a protocol. The coordination is related to the management of people, their activities and resources; And Cooperation is a joint effort in a shared space to achieve some goal. Thus, in relation to driver communication, it tried to associate aspects that interfere with communication between members. So, language, communication styles, social capital and knowledge sharing were selected. The driver coordination includes the relevant aspects in the coordination of distributed teams. Thus, the following: power distance, uncertainty avoidance, availability and different working practices were considered as important. The last driver of this perspective is cooperation, which consists of aspects of cooperation between members of a team of GSD. They are individualism x collectivism, trust, work planning, perception of time, sharing of knowledge and social capital.

The Personal Perspective was defined because when GSD is considered, there may be several people involved and that they, in turn, can be from different locations. This can lead to situations where there is a need to deal with people with different characteristics and / or values. The following describes the main features that were associated with this perspective. The individual aspects are: determination, indulgence, proactivity $\mathrm{x}$ reactivity, controllability, stress, emotional x neutral culture, leadership, motivation and creativity. In addition, the values, which according Hofstede et al (2010), are general tendencies to prefer certain states of affairs to others, include belief or religion, tradition, morals and ethics.

Depending on the individual culture, people can have different behaviors and thoughts and can lead to conflicts and problems with other members of a team of GSD. Thus, the manager of a distributed team must know these differences to better deal with situations in which they occur and avoid conflicts or misunderstanding among stakeholders.

For a project to reach the expected success, in addition to collaboration, personal characteristics involved, there are other factors that can influence the work teams. This refers to elements that often are beyond the will of those involved but that must be observed and respected to avoid future legal problems, and also understand the possible limitations arising from the education and training of people. Thus, External Perspective was defined to consider legislation, economics and education as drivers. At the legislation driver are included the external aspects of the laws governing each region: pay differences, bureaucracy, intellectual capital and intellectual property. The second driver of this set is related to the economy of a region. The last driver of this classification is related to education. It contains aspects related to education and the kind of education that is offered.

\section{CONCLUSION}

For the success of Global Software Development, it is necessary to solve several problems arising from geographical, temporal and cultural dispersion (Ebert et al., 2016). Part of these problems is derived from socio-cultural differences that may exist between the members of the distributed team. 
Although several authors (MacGregor et al., 2005; Casey, 2011; Huzita et al., 2012) mention sociocultural aspects that can influence the GSD without performing a classification. Thus, this study aimed to point out the sociocultural aspects that influence the GSD team's performance and provide a possible classification regarding these aspects. The main contributions refer to the systematization of social and cultural aspects in the literature, the identification of aspects and relationship with the GSD. The classification was proposed to facilitate the understanding of the impacts that the sociocultural aspects can cause in distributed teams.

In this classification, it was suggested different levels (Perspective, driver, aspects), each one separated into subsets. The Perspective separate the aspects using as a rule the aspects most related to the cooperation between individuals, they were related to the individual (more staff) and external factors. Through this separation, it is possible to see which aspects can influence different fronts (Perspective), in the performance of a DGS team and can support the allocation of human resources, the management of a distributed team and decision-making.

The major threats to the validity of this study refer to: i) set of listed aspects. Aspects used were obtained from a systematic mapping. Thus, in the case of a systematic mapping, this is subject to limitations with respect to such as availability of information, search engines and String used in the search, which, if changed, can result in change of results. ii) Classification criteria. The classification presented here is a classification suggested by the authors.

The classification showed is one of the possible being used, and there may be others, depending on the individual interpretation and / or groups of criteria used. Based on the limitations and conclusions obtained it was identified as future work the validation of the classification presented, along with distributed development managers.

\section{ACKNOWLEDGEMENTS}

The authors thank to Elisa Hatsue Moriya Huzita (elisa.h.m.huzita@gmail.com), for her help to the development of this article.

\section{REFERENCES}

Agerfalk, P. J., Fitzgerald, B., Holmstrom Olsson, H., Lings, B., Lundell, B., Ó Conchúir, E. (2005). A framework for considering opportunities and threats in distributed software development. In: Proceedings of the International Workshop on Distributed Software Development, 47-61, Paris, France, Austrian Computer Society.

Avram, G., Wulf, V. (2011). Guest editorial: Studying work practices in Global Software Engineering. Information and Software Technology, 53(9), 949-954. DOI:10.1016/j.infsof.2011.01.010.

Babar, M. A., Lescher, C. (2014). Global software engineering: Identifying challenges is important and providing solutions is even better. Information and Software Technology, 56(1), 1-5. DOI:10.1016/j. infsof.2013.10.002.

Babar, M. A., and Zahedi, M. (2013). Understanding Structures and Affordances of Extended Teams in Global Software Development. 2013 IEEE 8th International Conference on Global Software Engineering, 226-235. DOI:10.1109/ICGSE.2013.36. 
Bellur, U. (2006). An academic perspective on globalization in the software industry. In: Proceedings of 30th Annual International Computer Software and Applications Conference COMPSAC '06. 53-54. DOI: 10.1109/COMPSAC.2006.20.

Boden, A., Avram, G., Bannon, L., Wulf, V. (2009). Knowledge Management in Distributed Software

Development Teams - Does Culture Matter? 2009 Fourth IEEE International Conference on Global Software Engineering, 18-27. DOI:10.1109/ICGSE.2009.10

Carmel, E. (1999). Global Software Teams: Collaborating Across Borders and Time Zones. EUA: Prentice Hall, ISBN: 0-13-924218-X. 269 p.

Casey, V. (2011). Imparting the Importance of Culture to Global Software Development. ACM Inroads, 1(3), 51-57. DOI: $10.1145 / 1835428.1835443$.

Cibotto, R. A. G., Pagno, R. T., Tait, T. F. C., Huzita, E. H. M. (2009). Uma Análise da Dimensão SócioCultural no Desenvolvimento Distribuído de Software. $V$ Workshop Um Olhar Sociotécnico Sobre a Engenharia de Software - WOSES, 96-107.

Damian, D. (2002). Workshop on Global Software Development. In: ICSE '02 Proceedings of the 24th International Conference on Software Engineering, IEEE Computer Society, USA, 667-668. DOI: $10.1145 / 581339.581435$.

Da Silva, F. Q. B., Costa, C., Franca, A. C. C., Prikladnicki, R. (2010). Challenges and Solutions in Distributed Software Development Project Management: A Systematic Literature Review. 2010 5th IEEE International Conference on Global Software Engineering, 87-96. DOI:10.1109/ICGSE.2010.18.

Ebert, C., Kuhrmann, M., Prikladnicki, R. (2016). Global Software Engineering: An Industry Perspective. IEEE Software, 33(1), 105-108. DOI: 10.1109/MS.2016.27.

Ellis, C. A., Gibbs, S. J, Rein, G. L. (1991). Groupware: Some issues and experiences. Communications of the ACM, 34(1), 39-58. DOI: 10.1145/99977.99987.

Fuks, H., Raposo, A. B., Gerosa, M. A., Lucena, C. J. P. (2005). Applying the 3C Model to Groupware Development. International Journal of Cooperative Information Systems, 14(2-3), 299-328. DOI: 10.1142/ S0218843005001171.

Herbsleb, J. D., Moitra, D. (2001). Guest Editors' Introduction: Global Software Development. IEEE Software, 18(2), 16-20. DOI: 10.1109/52.914732.

Hofstede, G., Hofstede, G. J., Minkov, M. (2010). Cultures and Organizations: Software of the mind. McGraw-Hill, 3a ed. ISBN: 978-0071664189, 561p.

Huang, H., Trauth, E. M. (2007). Cultural Influences and Globally Distributed Information Systems Development : Experiences from Chinese IT Professionals. Proceedings of the 2007 ACM SIGMIS CPR conference on Computer personnel research: The global information technology workforce, 36-45. DOI: $10.1145 / 1235000.1235008$.

Huzita, E. H. M., Leal, G. C. L., Balancieri, R., Tait, T. F. C., Cardoza, E., Penteado, R. R. M., Vivian, R. L. (2012). Knowledge and Contextual Information Management in Global Software Development: Challenges and Perspectives. 2012 IEEE Seventh International Conference on Global Software Engineering Workshops, 43-48. DOI: 10.1109/ICGSEW.2012.12.

Jablokow, K., Myers, M. (2010). Managing Cognitive and Cultural Diversity in Global IT Teams. 2010 5th IEEE International Conference on Global Software Engineering, 77-86. DOI:10.1109/ICGSE.2010.17.

Karolak, D. W. (1999). Global Software Development: Managing Virtual Teams and Environments. IEEE Computer Society Press, 1 ed., ISBN: 0818687010. 
Kitchenham, B. (2004). Procedures for Performing Systematic Reviews. Joint Technical Report, Software Engineering Group, Department of Computer Science, Keele University, Empirical Software Engineering, National ICT Australia Ltd., Australia, ISSN: 1353-7776. [On-Line]. http://csnotes.upm.edu.my/kelasmaya/ pgkm20910.nsf/0/715071a8011d4c2f482577a700386d3a/\$FILE/10.1.1.122.3308[1].pdf

Kitchenham, B. A., Charters, S. (2007). Guidelines for Performing Systematic Literature Reviews in Software Engineering. Keele University \& University of Durham, EBSE Technical Report EBSE 2007-01.

Leal, G. C. L., Huzita, E. H. M., Tait, T. F. C. (2012). Globalization and Socio-Technical Aspects of Information Systems Development. In: Kalloniatis, C. Innovative Information Systems Modelling Techniques, ISBN 978-953-51-0644-9. DOI: 10.5772/36867.

Lee, I., Choi, G. W., Kim, J., Kim, S., Lee, K., Kim, D., Han, M., Park, S. Y., An, Y. (2008). Cultural Dimensions for User Experience: Cross-Country and Cross-Product Analysis of Users' Cultural Characteristics. BCS-HCI '08 Proceedings of the 22nd British HCI Group Annual Conference on People and Computers: Culture, Creativity, Interaction, 1, 3-12. ISBN: 978-1-906124-04-5.

Macgregor, E., Hsieh, Y., Kruchten, P. (2005). The Impact of Intercultural Factors on Global Software Development. Canadian Conference on Electrical and Computer Engineering, DOI: 10.1109/ CCECE.2005.1557127.

Moe, N. B., Smite, D. (2008). Understanding a lack of trust in global software teams: a multiple-case study. Software Process: Improvement and Practice, 13(3), 217-231. DOI: 10.1002/spip.378.

Oliveira, F. F., Antunes, J. C. P., Guizzardi, R. S. S. (2007). Towards a collaboration Ontology. In: 2nd Workshop on Ontologies and Metamodeling in Software and Data Engineering (WOMSDE), 97-108.

Olson, J. S., Olson, G. M. (2004). Culture Surprises in Remote Software Development Teams. Queue Distributed Development. 1(9), 52-59.

Prikladnicki, R., Audy, J, L, N., Evaristo, R. (2006). A Reference Model for Global Software Development: Findings from a Case Study. In: 2006 IEEE International Conference on Global Software Engineering (ICGSE'06), 18-28. DOI: 10.1109/ICGSE.2006.261212.

Prikladnicki, R., Evaristo, R., Gallagher, K., Lopes, L., Audy, J. L. N. (2005). The Role of Culture in Interpreting Qualitative Data: Methodological Issues in an Exploratory Study of Cross-Cultural Distributed Software Development. In: 13th Annual Cross-Cultural Meeting in Information Systems at ICIS, 2005, Las Vegas.

Prikladnicki, R., Carmel, E. (2014). The Emerging Brazilian I.T. Industry and its Time-Zone Proximity Advantage. Journal of Global Information Management, 22(1), p. 1-13. DOI: 10.4018/jgim.2014010101.

Sarker, S., Kirkeby, S., Chakraborty, S. (2007). Path to "Stardom" in Globally Distributed Teams : An Examination of a Knowledge-centered Perspective using Social Network Analysis., 2007 40th Annual Hawaii International Conference on System Sciences (HICSS'07). DOI: 10.1109/HICSS.2007.428.

Schwalbe, K. (2000). Information Technology Project Management. Course Technology Press, 1 ed., ISBN:076001180X. $561 \mathrm{p}$.

Vale, L., Beserra, P., Albuquerque, A. B. (2010). Relevant Skills to Requirement Analysts According to the Literature and the Project Managers Perspective. In: 2010 7th International Conference on the Quality of Information and Communications Technology (QUATIC 2010). DOI: 10.1109/QUATIC.2010.40. 


\section{APPENDIX}

S1. Abufardeh, S., Magel, K. (2010). The Impact of Global Software Cultural and Linguistic Aspects on Global Software Development Process (GSD): Issues and Challenges. 4th International Conference on New Trends in Information Science and Service Science, 133-138.

S2. Al-Ani, B., Marczak, S., Redmiles, D., Prikladnicki, R. (2014). Facilitating contagion trust through tools in Global Systems Engineering teams. Information and Software Technology, 56(3), 309-320. DOI:10.1016/j. infsof.2013.11.001

S3. Anticoli, L., Toppano, E. (2011). The Role of Culture in Collaborative Ontology Design. ISWSA '11 Proceedings of the 2011 International Conference on Intelligent Semantic Web-Services and Applications. DOI: $10.1145 / 1980822.1980826$.

S4. Ashman, H., Brailsford, T., Cristea, A., Sheng, Q. Z., Stewart, C., Toms, E. G., Wade, V. (2014). The Ethical and Social Implications of Personalization Technologies for e-Learning. Information \& Management, 51(6), 819-832. DOI: 10.1016/j.im.2014.04.003.

S5. Avram, G., Wulf, V. (2011). Description in the references.

S6. Babar, M. A., Lescher, C. (2014). Description in the references.

S7. Babar, M. A., Zahedi, M. (2013). Description in the references.

S8. Bailey, J. W. (2012). Self-Determination and Culture: An Intervening Variable. Lynchburg College 07. [On-Line]. https://www.lynchburg.edu/wp-content/uploads/volume-7-2012/BaileyW-Self-DeterminationCulture.pdf.

S9. Baxter, G., Sommerville, I. (2011). Socio-technical systems: from design methods to systems engineering. Interacting with Computers, 23(1), 4-17. DOI:10.1016/j.intcom.2010.07.003

S10. Boden, A., Avram, G. (2009). Bridging Knowledge Distribution: The Role of Knowledge Brokers in Distributed Software Development Teams. 2009 ICSE Workshop on Cooperative and Human Aspects on Software Engineering, 8-11. DOI: 10.1109/CHASE.2009.5071402.

S11. Boden, A., Avram, G., Bannon, L., Wulf, V. (2009). Description in the references.

S12. Carmel, E., Agarwal, R. (2001). Tactical Approaches for Alleviating Distance in Global Software Development. IEEE Software, 18(2), 22-29. DOI: 10.1109/52.914734.

S13. Cibotto, R. A. G., Pagno, R. T., Tait, T. F. C., Huzita, E. H. M. (2009). Description in the references.

S14. De Oliveira, J. P. N. et al. (2013). Challenges in Management Conflict in Developing Distributed Software Project. IV CBSoft: Theory and Practice. In VII WDDS pp. 101-108 (Portuguese)

S15. Espinosa, J. A., DeLone, W., Lee, G. (2006). Global boundaries, task processes and IS project success: a field study. Information Technology \& People, 19(4), 345-370. DOI:10.1108/09593840610718036.

S16. Fernández-Sanz, L., Misra, S. (2012). Analysis of cultural and gender influences on teamwork performance for software requirements analysis in multinational environments. IET Software, 6(3), 167-175. DOI: 10.1049/ iet-sen.2011.0070.

S17. Gotel, O., Kulkarni, V., Scharff, C., Neak, L. (2008). Working Across Borders: Overcoming CulturallyBased Technology Challenges in Student Global Software Development. 2008 21st Conference on Software Engineering Education and Training, 33-40. DOI:10.1109/CSEET.2008.16

S18. Herbsleb, J. D. (2007). Description in the references.

S19. Hofstede, G., Hofstede, G. J., Minkov, M. (2010). Description in the references. 
S20. Holmstrom, H., Conchúir, E. Ó., Ågerfalk, P. J., Fitzgerald, B. (2006). Global Software Development Challenges: A Case Study on Temporal, Geographical and Socio-Cultural Distance. 2006 IEEE International Conference on Global Software Engineering (ICGSE2006). DOI: 10.1109/ICGSE.2006.261210.

S21. Huang, H., Trauth, E. M. (2007). Description in the references.

S22. Huzita, E. H. M., Alberto, C., Wiese, I. S., Tait, T. F. C, Quinaia, M., Schiavoni, F. L. (2008). A Set of Solutions to Support Distributed Software Development. In: II Workshop de Desenvolvimento Distribuído de Software (WDDS). (Portuguese)

S23. Jablokow, K., Myers, M. (2010). Description in the references.

S24. Krishna, S., Sahay, S., Walsham, G. (2004). Managing cross-cultural issues in global software outsourcing. Communications of the ACM - Human-Computer Etiquette, 47(4), 62-66. DOI: 10.1145/975817.975818.

S25 Kroll, J., Hess, E. R., Audy, J. L. N., Prikladnicki, R. (2011). Researching into Follow-the-Sun Software Development: Challenges and Opportunities. 2011 IEEE Sixth International Conference on Global Software Engineering, 60-65. DOI:10.1109/ICGSE.2011.31.

S26. Leal, G. C. L., Huzita, E. H. M., Tait, T. F. C. (2012). Description in the references.

S27. Lee, I., Choi, G. W., Kim, J., Kim, S., Lee, K., Kim, D., Han, M., Park, S. Y., An, Y. (2008). Description in the references.

S28. Leidner, D. E. (2010). Globalization, culture, and information: Towards global knowledge transparency. The Journal of Strategic Information Systems, 19(2), 69-77. DOI:10.1016/j.jsis.2010.02.006.

S29. Macgregor, E., Hsieh, Y., Kruchten, P. (2005). Description in the references.

S30. Nguyen-Duc, A., Cruzes, D. S, Conradi, R. (2014). The impact of global dispersion on coordination, team performance and software quality: A systematic literature review. Information and Software Technology. 57, 277-294. DOI: 10.1016/j.infsof.2014.06.002.

S31. Olson, J. S., Olson, G. M. (2004). Description in the references.

S32. Pirkkalainen, H., Pawlowski, J. M. (2014). Global social knowledge management: Understanding barriers for global workers utilizing social software. Computers in Human Behavior, 30, 637-647. DOI: 10.1016/j. chb.2013.07.041.

S33. Raju, R. (2012). Intercultural Communication Training in IT Outsourcing Companies in India: A Case Study. IEEE Transactions on Professional Communication, 55(3), 262-274. DOI:10.1109/TPC.2012.2207834

S34. Ramingwong, S., Ramingwong, L. (2011). Culturally Influenced Risk Exposure: A New Approach to Tackle Risks in Offshore Outsourcing. 2011 International Conference on Information Science and Applications, 1-5. DOI: 10.1109/ICISA.2011.5772319.

S35. Ramingwong, S., Sajeev, A. S. M. (2010). Influence of culture on risks in offshore outsourcing of software projects: A quantitative study on mum effect. 2010 2nd IEEE International Conference on Information Management and Engineering, 401-404. DOI:10.1109/ICIME.2010.5478107.

S36. Ribeiro, B., Elias, G. (2011). Use of non-technical attributes in the Allocation Team in Development Projects Distributed Software. In: V Workshop de Desenvolvimento Distribuido de Software, 2011, São Paulo. (Portuguese)

S37. Santos, A.A., Andrade, M. F. M., Santos, V. da S., Oliveira, E. A. D. A. Q. (2007). Analysis of Organizational Culture: from the point of view of the board of a third sector organization. XII Encontro Latino Americano de Iniciação Científica e VIII Encontro Latino Americano de Pós-Graduação, 4-7. (Portuguese)

S38. Sarker, S., Kirkeby, S., Chakraborty, S. (2007). Description in the references.

S39. Soares, P. H. (2011). A strategy to address socio-cultural aspects in the distributed software development. Master Thesis. State University of Maringá (Portuguese) 
S40. Vale, L., Beserra, P., Bessa, A. (2010). Relevant skills requirements analysts according to the literature and the perspectives of Project Managers". In: VI Workshop "Um Olhar Sociotécnico sobre a Engenharia de Software”" (WOSES 2010), (Portuguese).

S41. Vatrapu, R. K., Suthers, D. D. (2010). Cultural influences in collaborative information sharing and organization. ICIC '10 Proceedings of the 3rd International Conference on Intercultural Collaboration, 161170. DOI: $10.1145 / 1841853.1841877$.

S42. Verner, J. M., Brereton, O. P., Kitchenham, B. A., Turner, M. and Niazi, M. (2014). Risks and risk mitigation in global software development: A tertiary study. Information and Software Technology, 56(1), 54-78. DOI: 10.1016/j.infsof.2013.06.005.

S43. Zeid, A., El-Bahey, R. (2013). Establishing a global software development course: A cultural perspective. 2013 IEEE Frontiers in Education Conference (FIE), 1695-1701. DOI: 10.1109/FIE.2013.6685126. 